\title{
Effects of Urban Morphology Changes on Ventilation: Studies in Wind Tunnel
}

\author{
Patricia Regina Chaves Drach ${ }^{1,2}$, Gisele Silva Barbosa ${ }^{2}$ and Oscar Daniel Corbella ${ }^{1}$ \\ 1. Post-GraduateProgram in Urbanism, Federal University of Rio de Janeiro, Rio de Janeiro 25645-560, Brazil \\ 2. Urban Engineering Program, Federal University of Rio de Janeiro, Rio de Janeiro 25645-560, Brazil
}

\begin{abstract}
This paper presents study of the effects of urban morphology changes on ventilation dynamics through a comparative study between blocks of Copacabana and Ipanema neighborhoods, located in Rio de Janeiro City, Brazil. The study was developed with the aid of experimental simulations in a wind tunnel, taking into account the urban morphology and its relations to open spaces. A diagnosis was produced through the exam of the wind effects in relation to the volume of built and non-built spaces. The effects were classified as positive or negative, in relation to the tropical climate. At first, both blocks studied, one in Ipanema and one in Copacabana, were selected according to common characteristics, which establish a relation between the two regions, such as the distance to the beach and the presence of a public square. The results confirmed our expectations showing Ipanema as a more ventilated area.
\end{abstract}

Key words: Ventilation, wind tunnel, urban morphology, urban micro-climate.

\section{Introduction}

This work is part of the studies developed by Wind Tunnel Laboratory, School of Architecture and Urbanism at UFRJ (Federal University of Rio de Janeiro). Experimental simulations were developed in architecture and urbanism aiming to evaluate actual and possible future scenarios, including proposed changes to promote increased ventilation [1].

Specific models representing buildings and urban areas were developed to the simulations using the wind tunnel. These models must comply with the appropriate size in relation to the test table of wind tunnel and be sufficiently resistant to deal with the velocities inside the tunnel. The results are used to give a qualitative diagnosis of the region measured in relation to the wind effects at the pedestrian level. The visualization method used was wind erosion or sand drag. From these experiments, the effects of wind in the vicinity of built volumes, vegetation and open spaces, are classified as positive or negative, in relation to the

Corresponding author: Patricia Regina Chaves Drach, D.Sc., research fields: sustainable architecture and urbanism, and urban microclimate. E-mail: patricia.drach@gmail.com. tropical climate, for various proposals and existing urban provisions. Through experiments, it is possible to select the best setting, which is the one that presents more intense and distributed ventilation.

The proposal presented in this article refers to a comparison between the blocks of the neighborhoods of Copacabana and Ipanema in the southern area, Zona Sul, of Rio de Janeiro City. It takes into account the urban morphology and its relation to the open spaces.

During the beginning of their occupation, Copacabana and Ipanema [2], both on the seaside area, were subject to different zoning laws [3,4] and this fact is reflected in their current morphology (urban networks).

Even being so close physically (Fig. 1), some striking variations were able to define these two neighborhoods in a so different way. In this work, one city block of each one was analyzed in relation to the ventilation inside the wind tunnel.

In practice, it is observed more intense and better distributed ventilation in internal blocks of Ipanema, compared with the ones of Copacabana. Although both neighborhoods are located in front of a beach, in Ipanema, 


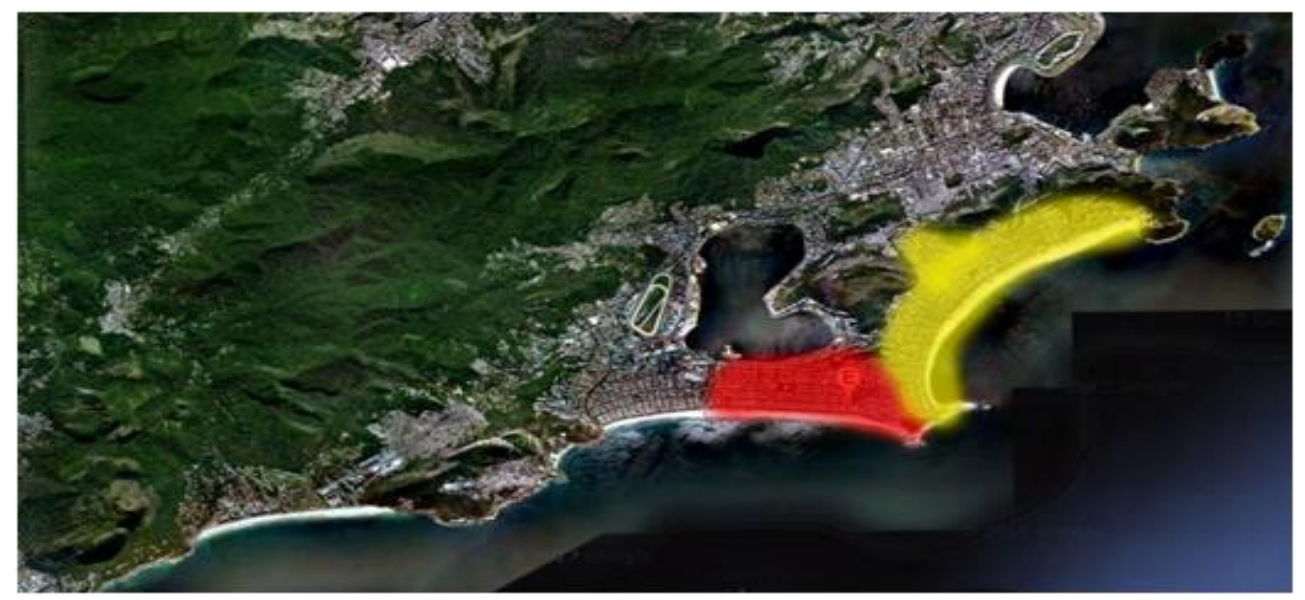

Fig. 1 Copacabana (in yellow) and Ipanema (in red) neighborhoods, side by side.

Source: Google Earth, 2013.

the immense wall of buildings along the waterfront as it can be noticed in Copacabana is not observed. In the blocks inside the neighborhood of Ipanema, there is also a distance between the buildings and they are not, in most cases, as close as it can be observed in Copacabana. The intention here was to observe through experimental simulations how the urban morphology is able to interfere with the results of the permeability of the urban mesh in relation to the wind.

The results confirmed our expectations showing Ipanema as a more ventilated area for the velocities and directions studied.

\section{Influence of Urban Morphology on Local Climate}

The local climatic factors, which can be seen on a small area, such as a city, neighborhood, block and street, influence and determine the microclimate. Therefore, the topography, the soil surface (both natural and built) and the vegetation directly influence this local climate.

Thus, the urban morphology is directly related to the quality of life in cities and can interfere with mobility issues and environmental comfort. The choices and outcomes of urban form can improve or worsen life quality, depending on their adequacy to the local needs. For example, a major pathway may facilitate the movement of automobiles and efficiently connect the neighborhoods of a city to its urban center. Conversely, this same pathway may hinder internal transportation, mostly on foot or bicycle through the neighborhoods crossed by it. In these cases, the appropriate urban planning solutions may indicate intervention into the urban fabric to deal with the problems to produce effects capable of reconciling the issue. Allowed internal access between neighborhoods and safe crossings for cyclists and pedestrians can be some of the resources to deal with this issue.

Changes in urban morphology can promote microclimate changes and affect the mobility. In some cases, particularly in cold regions, the temperature rises because the densification of a particular region may be beneficial or minor. Often, this can be used as an ally, even accounting for the possibility of reducing energy consumption. In these cases, caution in relation to the blocking of ventilation, which could result in increasing pollution, given the difficulty of dispersion of gases and pollutants, should be necessary. In tropical countries, such as Brazil, the densification process has shown increasing temperature in the studied regions [5-7], which could also represent an increase in energy consumption.

During the 20th century, Brazilian cities grew significantly: the majority of these cities developed without proper planning [8]. Thus, in many cases, the urban development was conducted according to the 
interests of real estate corporations. Thus, in several neighborhoods with high commercial value, aesthetics of morphology was prioritized. In these neighborhoods, wide roads and tree planting among others are part of the dominant landscape. By contrast, the feedback of the buildings and the spacing between them are subject to a minimum or no control. In these regions, big and high constructed areas are the best option for real estate.

In Brazilian scenario, urban legislation, although defined by region, shows some variability with height and width between the buildings, but it is here noted that these distinctions are always or almost never related to climate or cultural local characteristics.

However, in general, current laws are lax regarding jigs and spaces between buildings. Therefore, although they are fulfilled in part, the laws allow tall buildings in residential neighborhoods with a very small gap between the buildings, sometimes, even getting to allow to locate them side by side [9]. In addition, many "clever" builders circumvent the rules by building new constructions over old buildings, which were built before the current laws, as if they were only reforms taking advantage of the old laws, which were less rigid.

Thus, we stumble sometimes, with situations of absence of spacing between the buildings, or even where the proportionality between the height of buildings $(H)$ and the space between buildings $(W)$ reaches extremely low levels.

The ratio of width of the roads and the height of

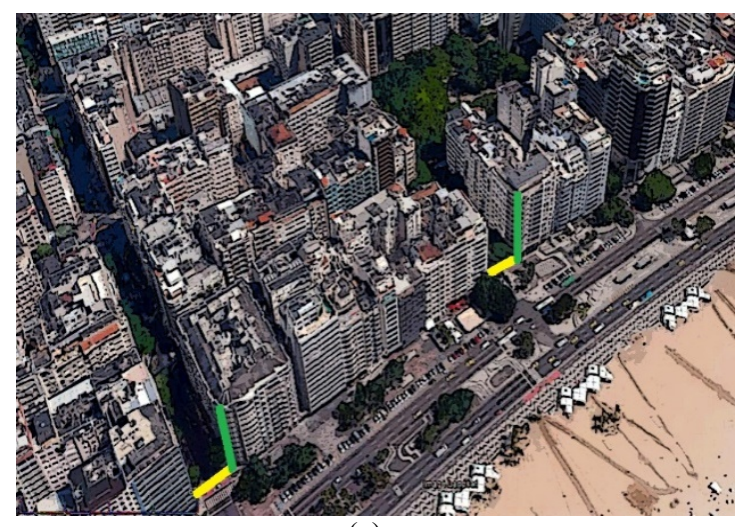

(a)

Fig. 2 Seafront of: (a) Copacabana beach; (b) Ipanema beach. Source: Google Earth, 2013. buildings $(W / H)$ can be identified as a helpful way to mitigate the effect of urban heat island. The $W / H$ ratio is directly related to the absorption of solar radiation and long-wave process (emitted by the surfaces of buildings and soil) and interferes with the heat loss due to wind and anthropogenic heat production [10]. Romero [9] defines and classifies the $W / H$ ratio as claustrophobic for $W / H<1$ and expansive for the $W / H>6$. In Fig. 2, the seafront of the two beaches can be observed, in which $W$ is yellow and $H$ is green. Copacabana appears with an almost solid mass along the waterfront without spacing between buildings and by establishing relations of $W / H$ around 0.37 in the wider and narrower streets at 0.28 . Ipanema presents a more differentiated occupation, with buildings of four floors with and without spacing between them still predominating. In addition, the presence of some 12-floor buildings must respect a minimum distance. The $W / H$ ratio calculated in cross streets to the waterfront ranged, on average, between 0.85 and 1.4, thus, classifying the neighborhood of Copacabana with higher percentage of situations of claustrophobic spaces if compared with the district of Ipanema.

The result from these inappropriate urban interventions or even its absence can be observed, especially in neighborhoods where the number of residents is much higher than its urban fabric can withstand. Thus, it is always the case of regions with much higher temperatures than one would expect for the location and without environmental comfort.

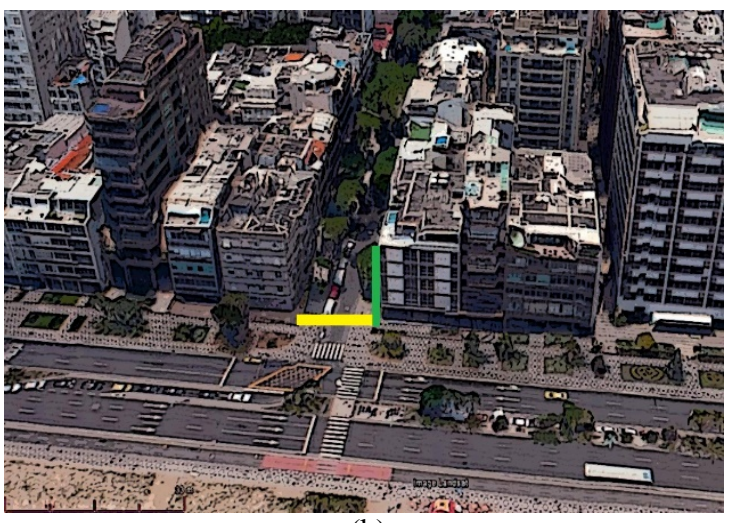

(b) 
Eventually, buildings form canyons, channeling ventilation or sometimes form barriers that prevent ventilation to penetrate into the neighborhood. This is the case of Copacabana, where the value of overlooking Copacabana beach resulted in the formation of extensive wall along the waterfront, which hinders ventilation on the inner streets of the neighborhood.

In the case of the regions studied in this article, the neighborhoods of Copacabana and Ipanema show the results of actions in their urban fabric on the morphology of the original neighborhoods. The neighborhoods were initially designed for low buildings (mostly homes) and relatively large streets (up to $15 \mathrm{~m}$ ) with trees along them. However, buildings today have a template for more than 12 floors and almost no space between the buildings. All these changes directly affect the local microclimate.

Some of the many aspects that suffer interference from changes in urban morphology are dynamic ventilation and air temperature increase resulting in the alteration of the local climate. This paper aims to show the influence of urban form on urban ventilation from simulations in wind tunnel. Thus, the importance of experimental simulations of wind tunnel as a tool to aid project decisions is shown.

\section{Wind Tunnel}

The WT (wind tunnel) of the FAU/UFRJ (School of Architecture and Urbanism of the Federal University of Rio de Janeiro) is an experimental tool that allows the understanding of the interaction of the flow of the wind with the buildings and their surroundings through the use of visualization techniques. Figs. 3 and 4 show a lower plan and a side view of the WT, respectively. In Fig. 4b, we note the detail of drawers sector seen without the access door (images adapted from the Wind Tunnel Project FAU/UFRJ, 2005). The Building Aerodynamics Laboratory-LAC/DECIV/PPGEC, from UFRGS developed the wind tunnel in 2005 [11]. The wind tunnel is mounted on an $8.80 \mathrm{~m} \times 7.60 \mathrm{~m}$ room on the ground floor of the FAU-UFRJ and works with velocities higher than $10 \mathrm{~m} / \mathrm{s}$, which is desirable for the testing of eolic erosion [12].

Figs. $5 \mathrm{a}$ and $5 \mathrm{~b}$ are photographic images of the side view and front view of the TV FAU/UFRJ: the test table can be observed in them. This has a swivel mechanism: the reduced models are positioned appropriately in relation to the wind direction according to the need of evaluation. In the design of a wind tunnel, the barrier layer is desirable that at least a portion of the flow-over develops minimum amounts of different types of roughening. Thus, the development flow takes place through a long roughened surface representing the existence of a built environment. In the photographs of Figs. 5c and 5d, barriers called turbulence generators, with the shape of a shark's fin (Fig. 5c), and the roughened surface (Fig. 5d) over which the flow is developed before reaching the test table can be observed.

\section{Eolic Erosion or Sand Drag Technique}

The technique of eolic erosion (or "dragging sand") can be of great help in understanding the paths that wind makes in the urban environment, as well as their entries and possible barriers [13]. With this technique, it is possible to observe in the pedestrian level, vented or sealed, depending on prevailing directions and velocities of the winds. The study of the areas where the sand accumulates combined with the study of solar radiation allows the identification of the possibility of heat island development, as well as areas where pollutants are concentrated.

The eolic erosion consists in applying the selected sand on all exposed surfaces of the model, and then, the wind tunnel is connected. For the experiments with this technique, tests were done to allow the definition of the material most appropriate to the experiment. In the first test of the wind tunnel with an urban model, sand with granulometry of $0.015 \mathrm{~mm}$ was used, but this had no significant displacement, even at the highest velocities. Further tests were made with other materials: 


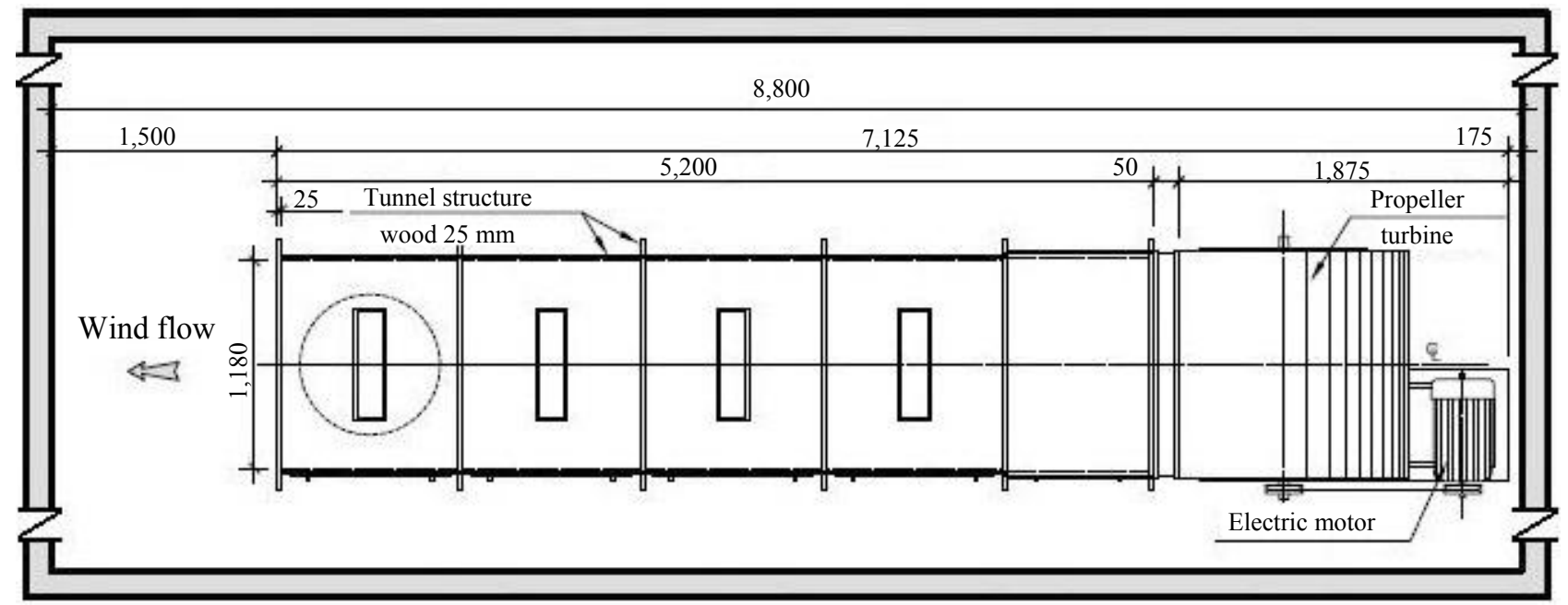

(a)

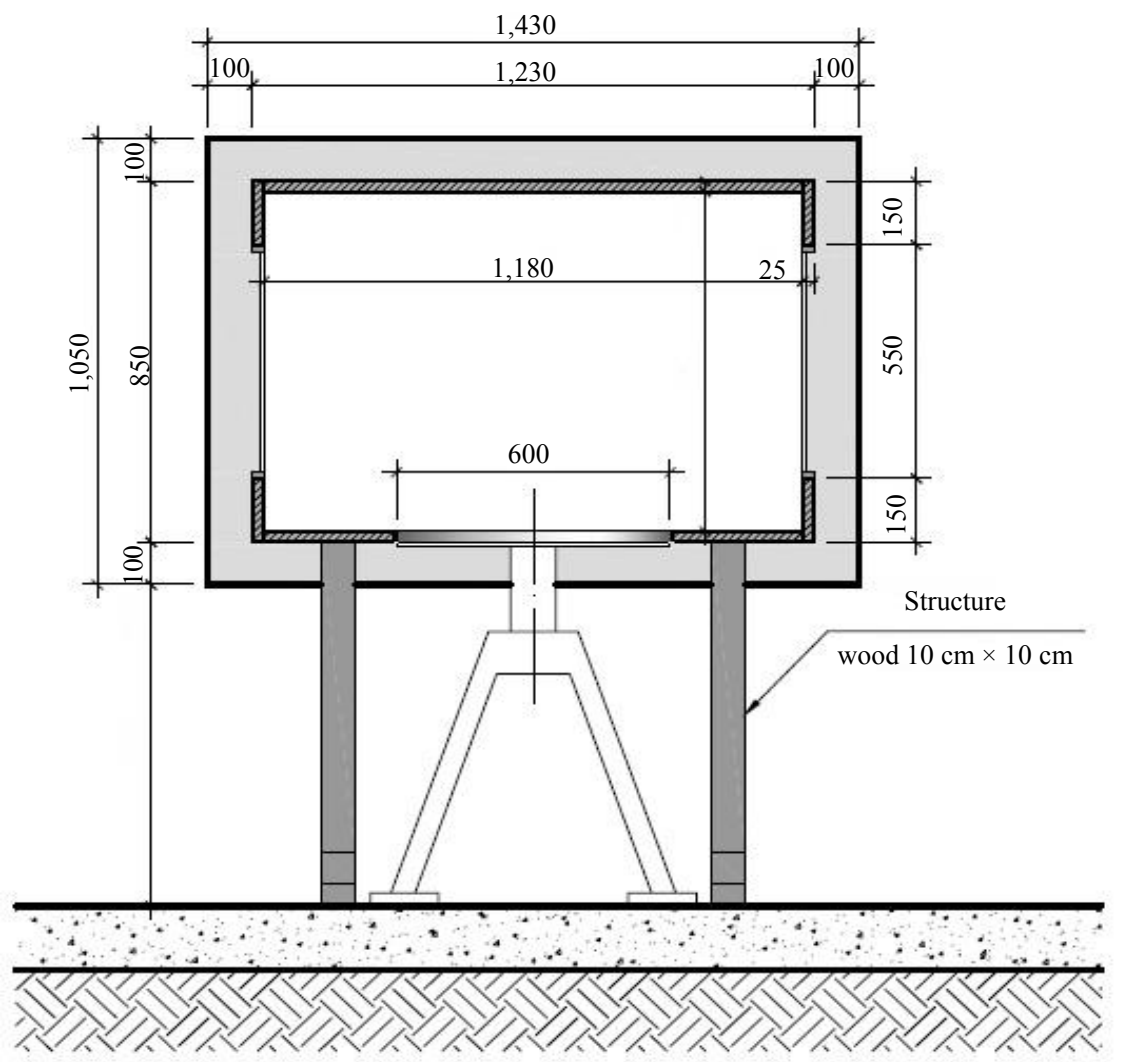

(b)

Fig. 3 The FAU/UFRJ wind tunnel: (a) floor plan; (b) section (units in mm).

Source: adapted from the Wind Tunnel Project-FAU/UFRJ, 2005.

clay $(0.0075 \mathrm{~mm})$, sand $(0.0075 \mathrm{~mm})$, a new test with sand $(0.015 \mathrm{~mm})$, talc and cement. In evaluating the pros and cons of each material in relation to the reality of the facilities of the tunnel, the adoption of smaller sand grain size was determined $(0.0075 \mathrm{~mm})$ : clear and fine sand was obtained with the use of sieves.
The studies on TV/FAU are developed with hypothetical and real space models. The experiments presented in Fig. 5 show the results obtained for the hypothetical urban space built with compact blocks and allow immediate observation of changing paths taken by the wind. The experiments were performed in series 
to allow the observer positioned in TV/FAU laboratory the immediate visualization of the changes drawn in the sand for the three scenarios. Altogether, they form the big "U" (Fig. 6a), where the accumulation of sand inside the joint as a result of lack of wind can be noticed. To promote ventilation in this place, in Fig. 6b, one of the blocks located upwind was removed, allowing the wind access to the interior of the joint and resulting in a new setting of the deposited sand. Fig. 6c presents the rotation of one of the sidewall plates, consequently showing a change in the distribution of sand in the base of the profile structure. In Fig. 6, the wind direction is indicated by the arrow, and less ventilated regions appear outlined, confirming that the dynamics of the wind varied only by changing the positioning of the blocks.

The results allow a qualitative assessment of the wind field and the observation of configurations that result in an increase or reduction in ventilation for both architectural and urban models. In the experiments

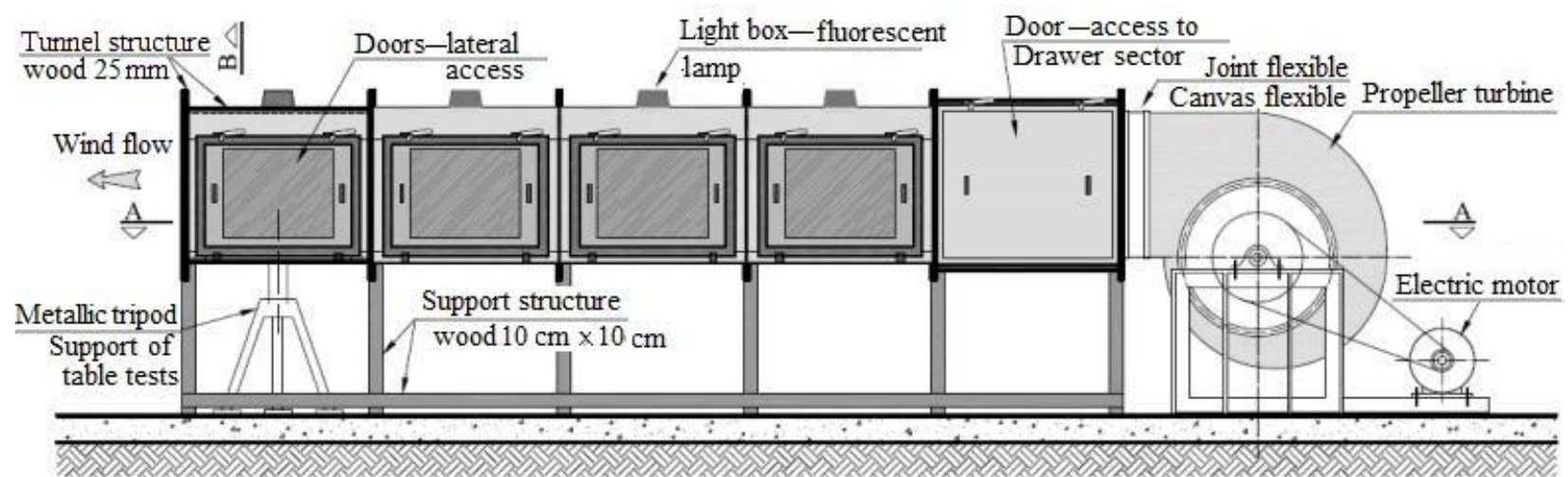

(a)

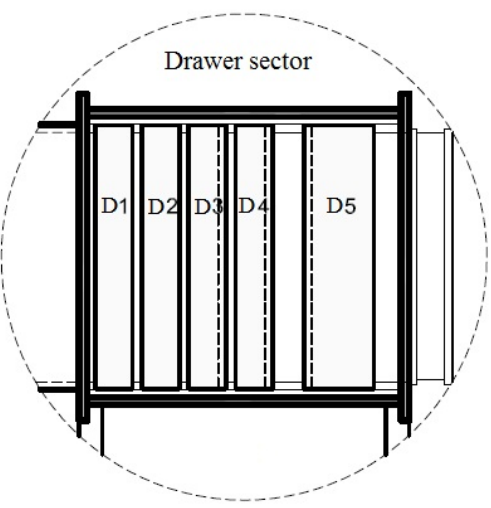

(b)

Fig. 4 Wind tunnel of the FAU/UFRJ: (a) side view of the wind tunnel of the FAU/UFRJ; (b) detail of drawers sector seen without the access door.

Source: design of Wind Tunnel FAU/UFRJ, 2005.

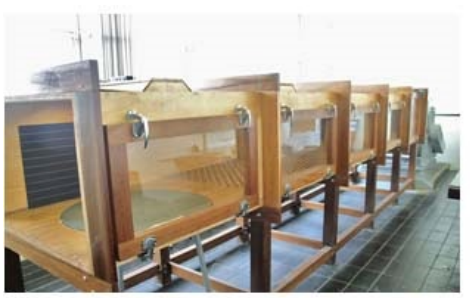

(a)

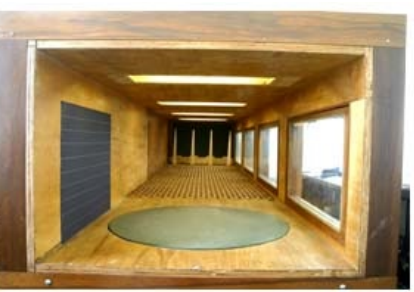

(b)

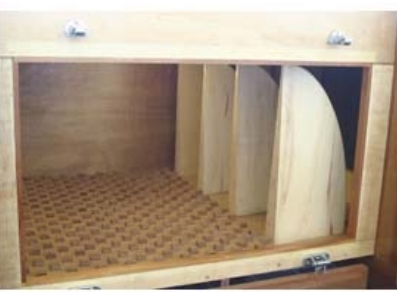

(c)

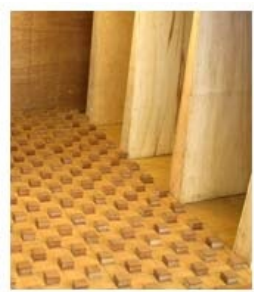

(d)

Fig. 5 The FAU/UFRJ wind tunnel: (a) side; (b) frontal views of the wind tunnel; (c) obstacles acting as turbulence generators; (d) rough surface. 


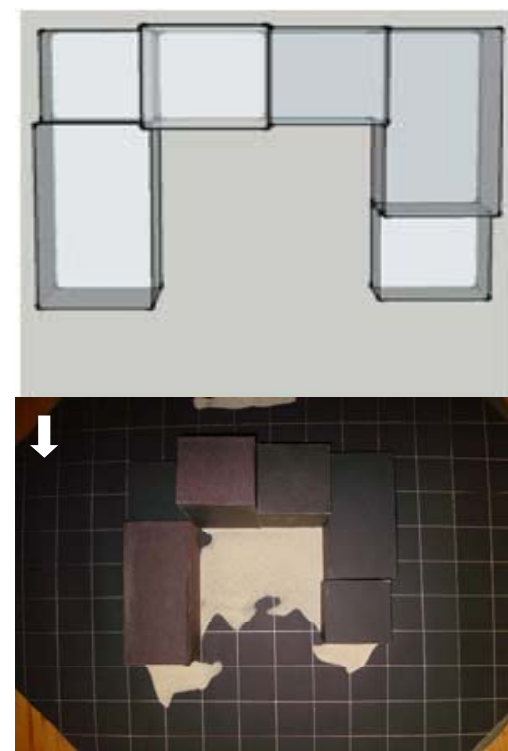

(a)

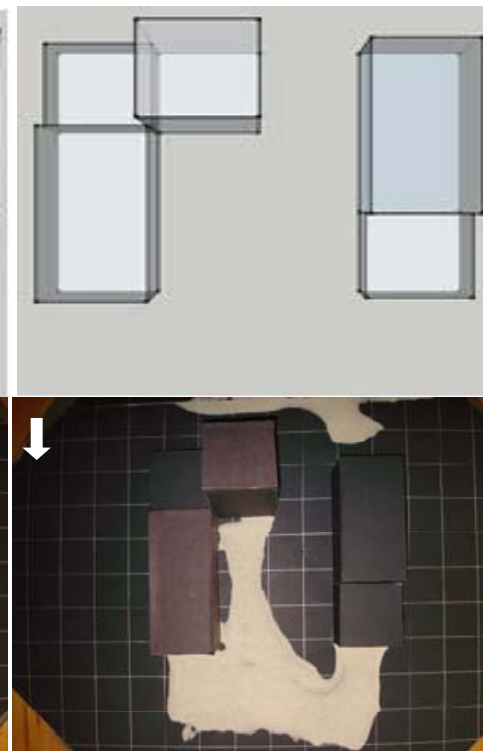

(b)

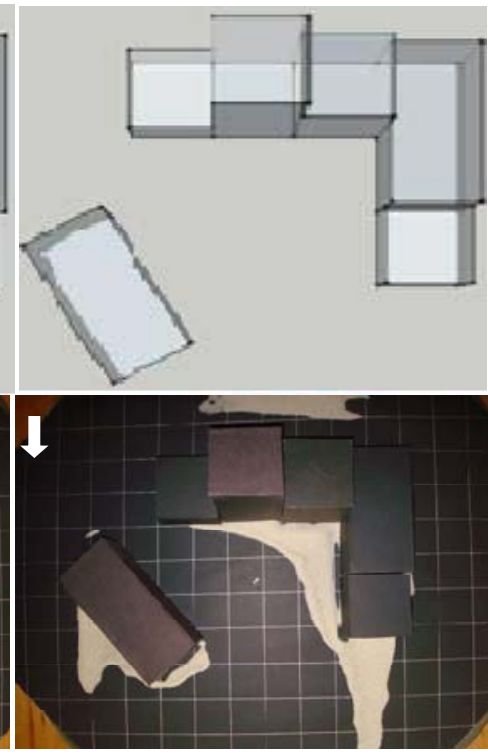

(c)

Fig. 6 The deposit of sand for each case indicated by a frame showing the least ventilated areas: (a) big "U" shape; (b) big "U” open; (c) big "U” open with rotation.

with the technique of eolic erosion, regions where the sand remains, despite the action of the wind on the whole, tend to indicate areas with poor ventilation, stagnant areas. Therefore, in studies in urban spaces, identifying ventilated or sealed areas inside the urban area according to the prevailing wind zones is possible. It is also possible to test different wind directions simply by rotating the test table of the wind tunnel and position the model to receive the desired direction of the wind. This study provides the best arrangements of the sets for different times of the year and times as well, suggesting the insertion or removal of obstacles in accordance with the need to ventilate a more or less specific region. These choices can allow the increase of environmental comfort for each case and the quality of the air breathed.

Experiments with eolic erosion make possible a qualitative analysis of ventilation in the pedestrian level. In these experiments, the visualization of ventilation inside the buildings as well as in the higher levels of studied area was not checked.

From the experiment and the identification of any critical points, it is possible to point and test interventions to help fit the needs of comfort and urban space, interference to be suggested for areas where there is no presence of wind varies according to climatic region in which they are located. For example, in hot humid climate regions, the need to induce a higher ventilation is known. The changes in the shape and position of obstacles, allowing redirection of the wind, can be studied to induce an increase of ventilation and shading to minimize the problem and prevent the formation of heat islands.

In the case of dry warm regions, ponds, fountains and spaces with water can be adopted, which helps to decrease the temperature by air humidification. In cold climates, these poorly ventilated areas are protected from the cold wind and can be defined as places of comfort areas.

In recognizing the ability of interference, even simple interventions or changes in wind fields, we can obtain tools to develop projects that balance the needs of users in place, thus reducing the energy consumption and the production of pollution.

\section{Brief Chronology Examination}

The occupation in Copacabana's area occurred later, compared with that in the rest of the city of Rio de Janeiro. The urbanization properly began in 1892 and the basic road network was already designed in 1894 
[4], although it was not implemented.

This late occupation may have been generated, at least, in part because of the location of the neighborhood. There was a narrow strip of land by the sea and it is surrounded by hills Cabritos, São João, Babilônia and Cantagalo. These hills make the access to the area difficult because the barriers of mountains, by one side, and the edge of the sea, by the other side, let only a narrow strip of land.

In the late 19th century, when other neighborhoods of the city were occupied, a large area of sand, called Sacopenapan (name in Tupi), was populated only by poor fishermen's houses and their small fields [3]. In the 17 th century, it found the statue of Our Lady of Copacabana, beloved saint in the region of Lake Titicaca, and the neighborhood was renamed Copacabana, which means "looking the lake" [3].

The opening of the Tunnel Real Grandeza, currently Alaor Prata Tunnel, known as Old Tunnel, in 1892, facilitated the access to Copacabana. Previously, the access was only possible through the Ladeira do Barroso, currently Ladeira do Leme, the first land access to Copacabana.

Also in 1892, the tramway company Ferro Carril Botanical Garden opened access to the neighborhood. Initially, there was an extension of a line of trams, still in animal traction, to the Serzedelo Correia's Square, and later, new extensions have been expanded to meet the two ends of the narrow strip of land, crossing all the beach: from Leme until the end of Nossa Senhora de Copacabana street (Posto VI).

In the case of Ipanema area, the lack of drinking water or constant flooding, to which the region was subjected, may have discouraged the occupation of the neighborhood. However, in terms of access, it was easier to be attained in comparison to Copacabana.

In the image of Fig. 7a (anonymous postcard), from 1930, the Atlantic Avenue and the Copacabana Palace Hotel, present even today, pointing mark in the history of the neighborhood, can be observed. In Fig. 7b, also in 1930s, the narrow strip of land, Copacabana, between the sea and mountains, can be seen.

The intense occupation of Copacabana had been observed in 1956 (Fig.8), and in the case of the elevation of the buildings, its designs were already very similar to that found nowadays [2].

Fig. 9 shows the urban occupation in Ipanema district area in 1930s (Fig. 9a) and 1950s (Fig. 9b) and Figs. 7-9 show a big difference in the occupation of these two regions.

In 1971, the current configuration, both of Atlantic Avenue as the Copacabana beach, or dual carriageway with central and wide sandy beach track construction, beyond the boardwalk, was inaugurated. After this opening, the elevation of height of buildings in Copacabana to greater than 12 floors, which dominated
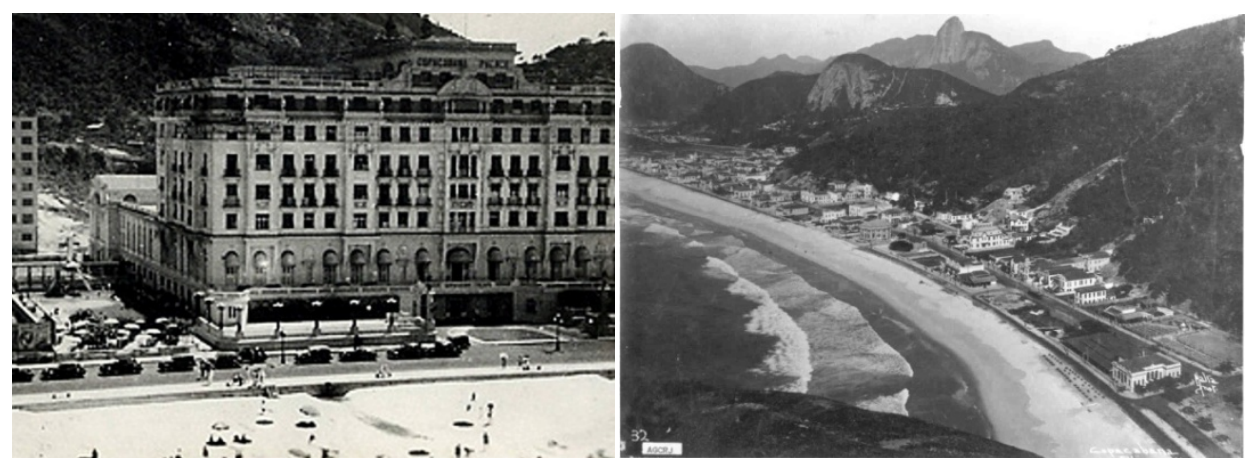

Fig. 7 The images of the seafront of Copacabana in 1930s.

Sources: anonymous post card (left) ${ }^{1}$ and Augusto Malta photographer (right) ${ }^{2}$.

\footnotetext{
${ }^{1}$ Avenida Atlântica_Copacabana, Rio de Janeiro, Brazil. Available: http://www.embarquenaviagem.com/2012/07/05/copacabana-aprincesinha-do-mar-completa-120-anos/.

${ }^{2}$ Avenida Vieira Souto - Ipanema, Rio de Janeiro, Brazil. Available: http://www.embarquenaviagem.com/2012/07/05/copacabana-aprincesinha-do-mar-completa-120-anos/.
} 


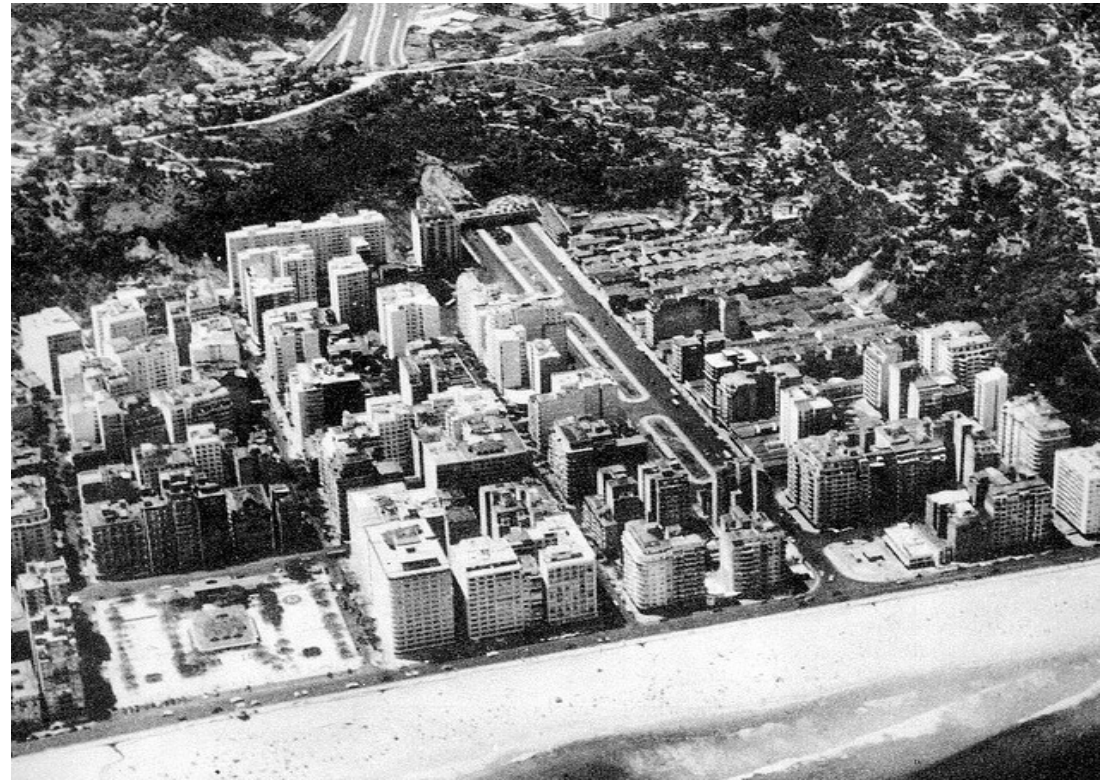

Fig. 8 The images of the seafront of Copacabana in 1950s.

Source: anonymous photo.

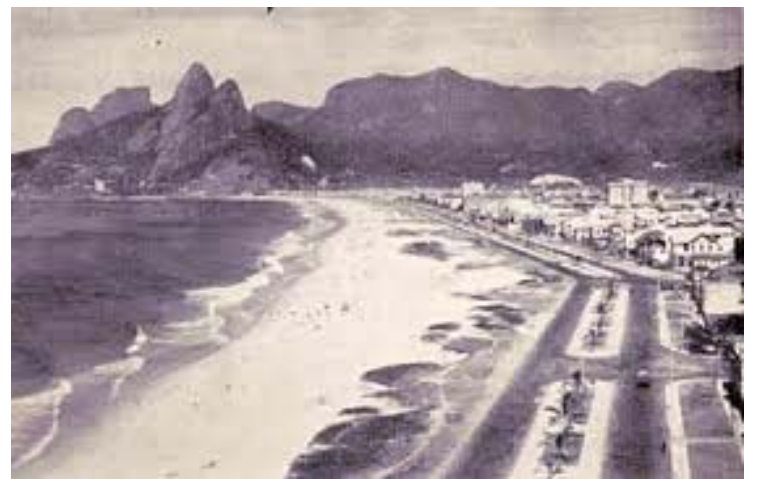

(a)

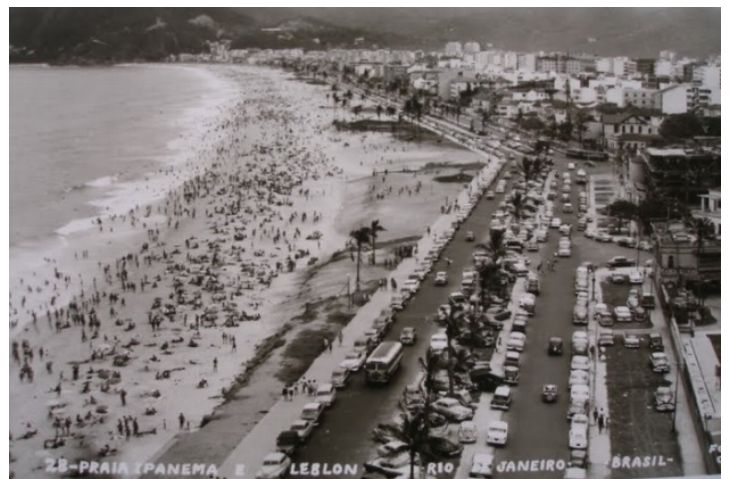

(b)

Fig. 9 Ipanema district, taken in: (a) 1930s; (b) 1950s.

Source: anonymous.

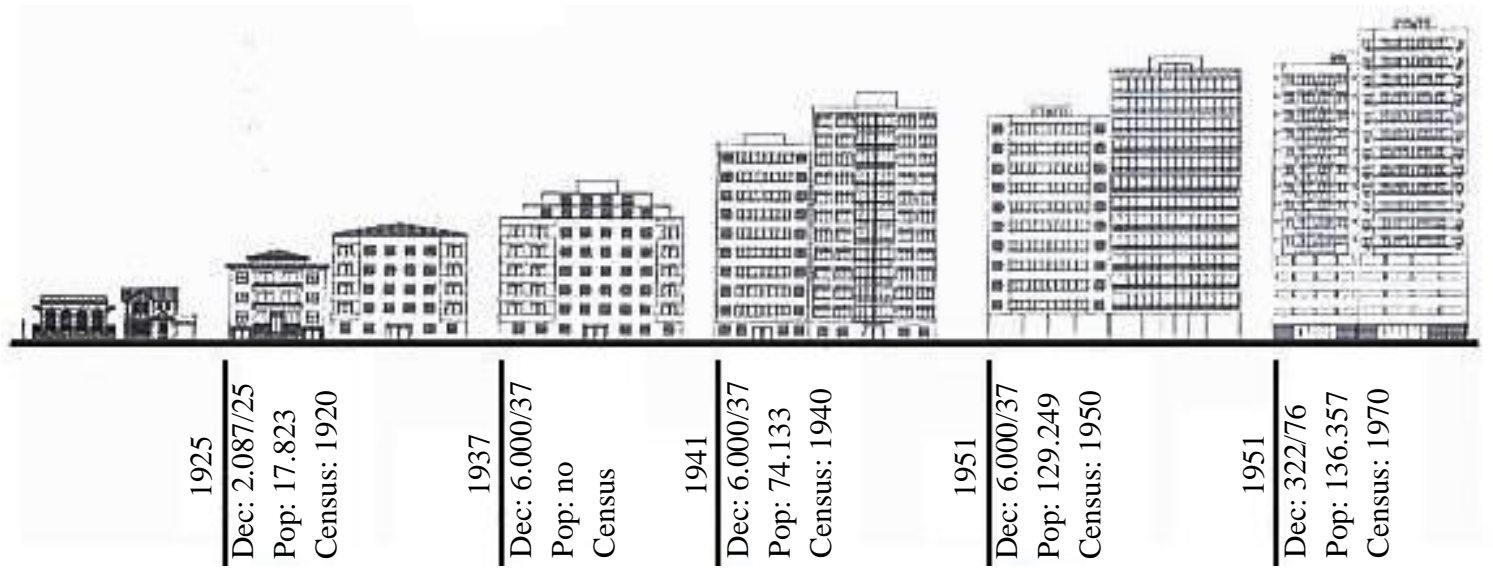

Fig. 10 Heights of buildings of Copacabana.

Source: Abreu [2]. 


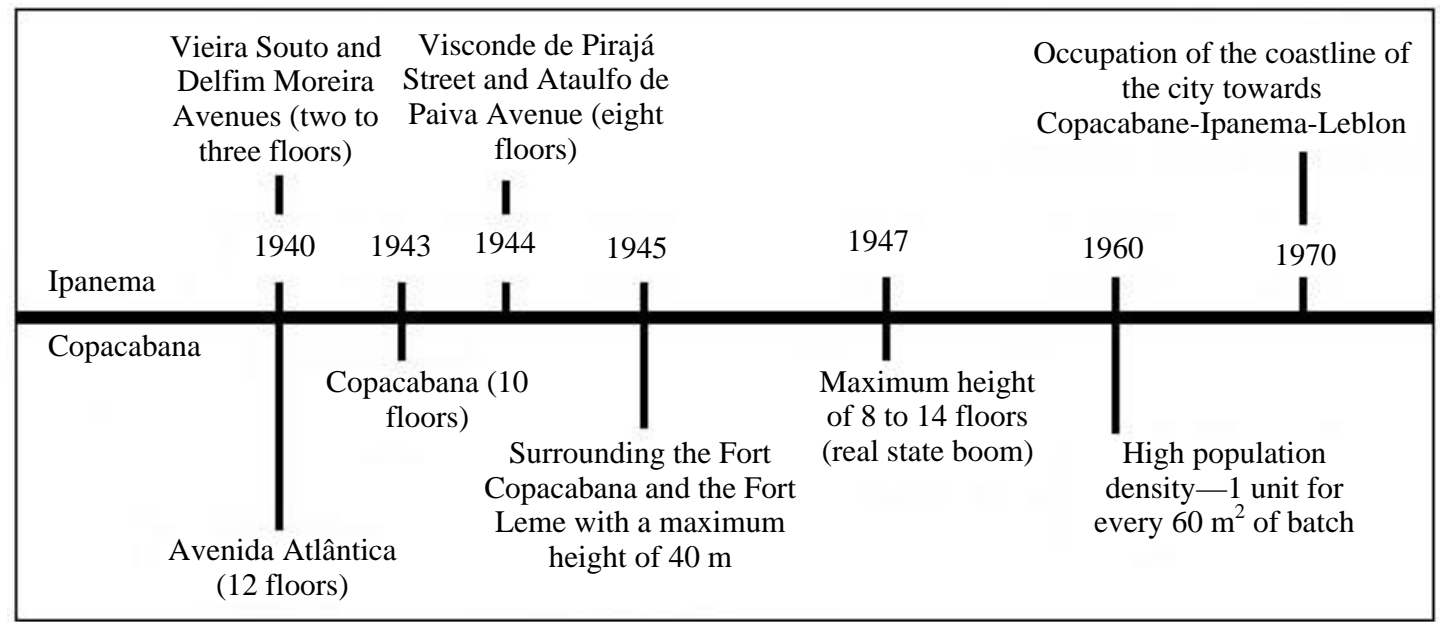

Fig. 11 The evolutionary line-heights of buildings of the two neighborhoods, Copacabana and Ipanema.

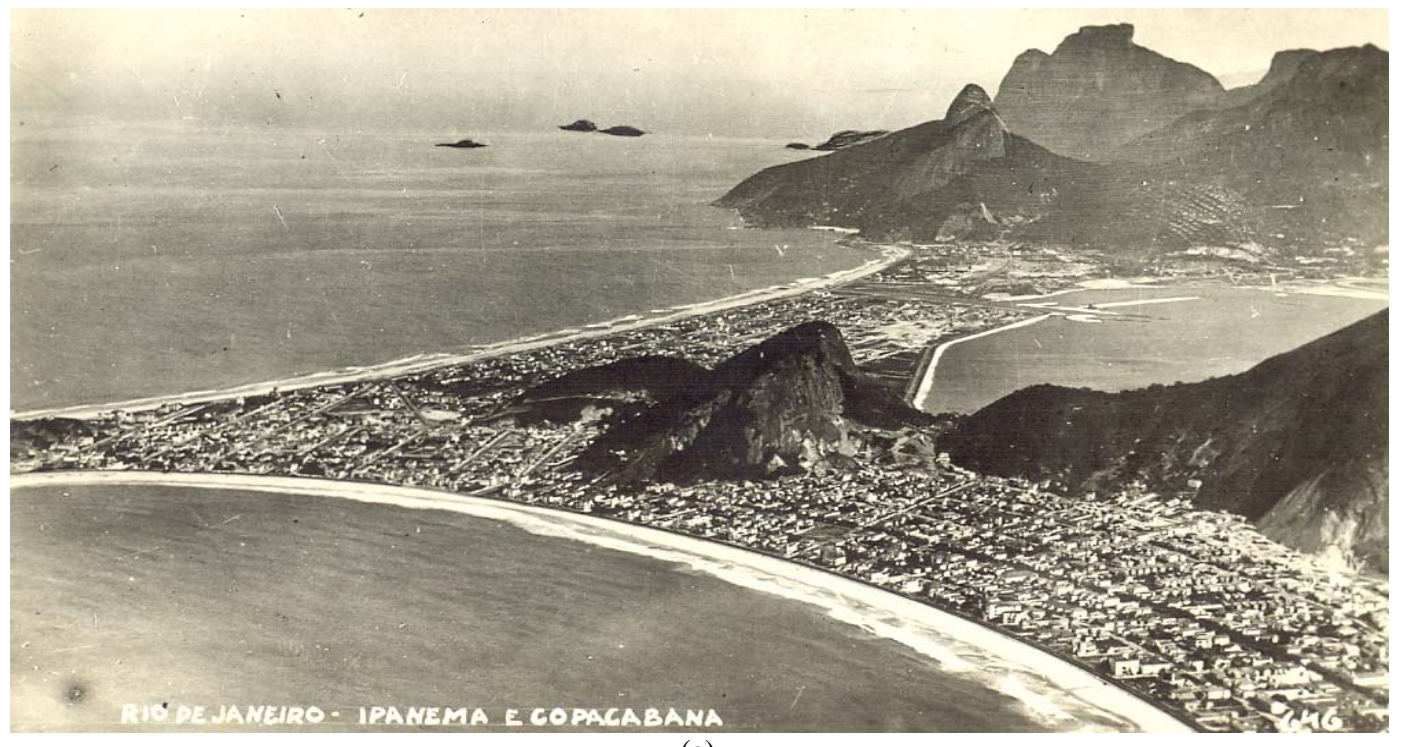

(a)

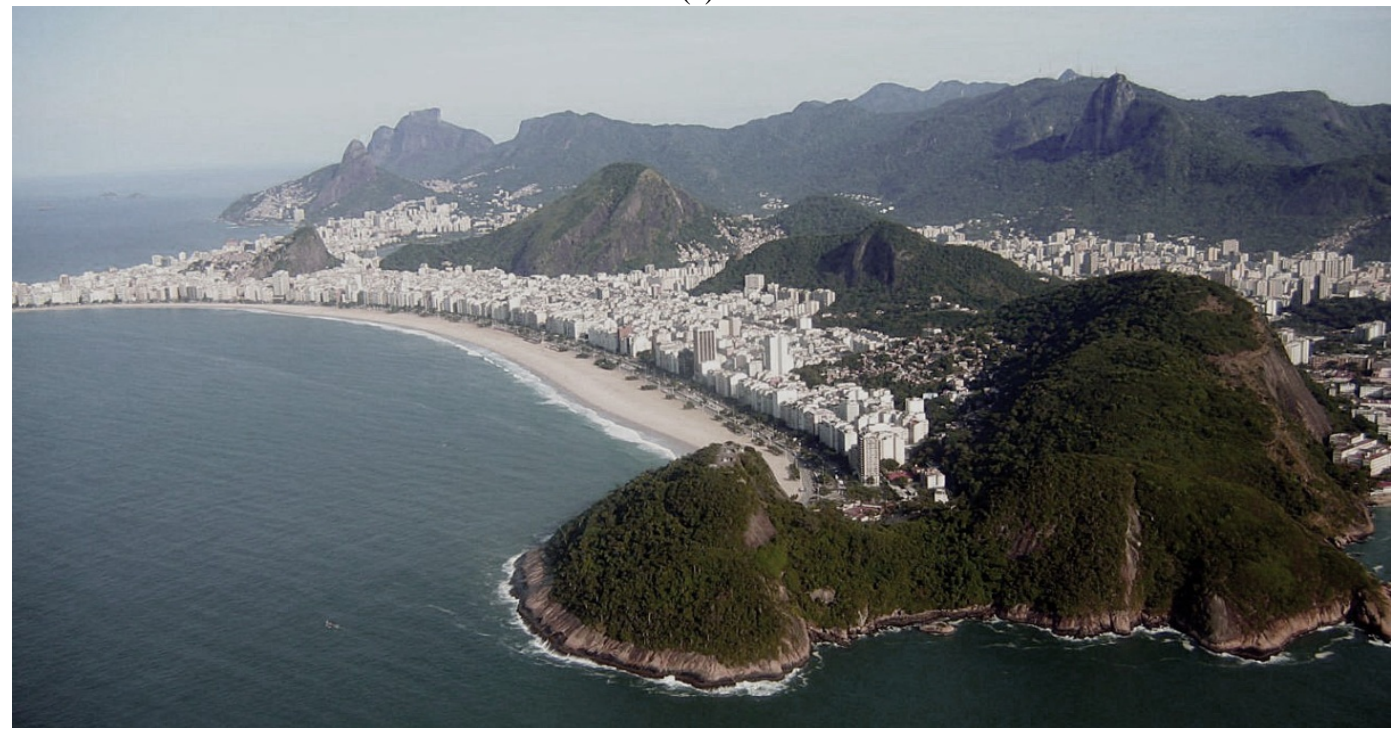

(b)

Fig. 12 Both districts side by side can be seen in the images: (a) in the 1950s; (b) today. 


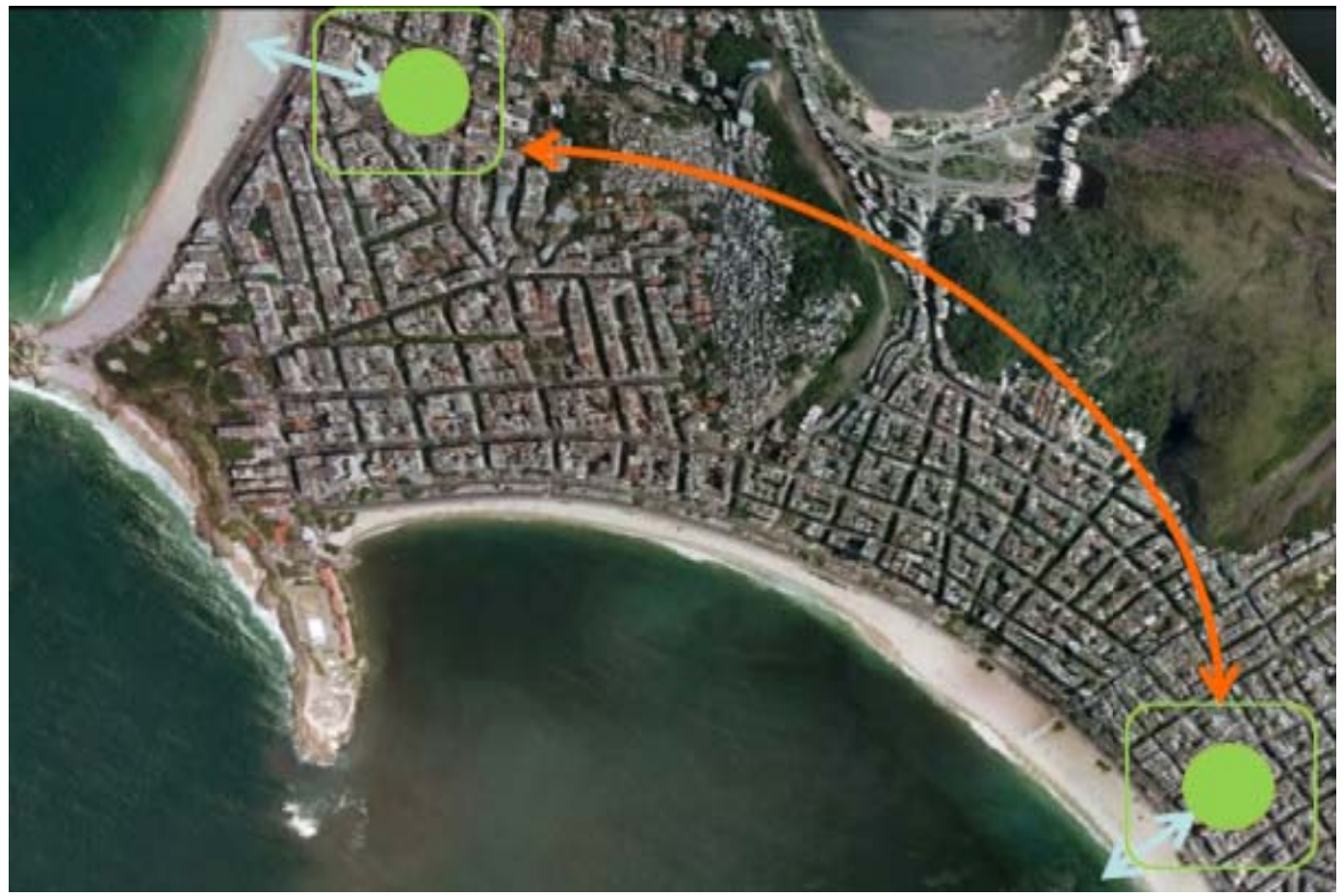

Fig. 13 Relation between the two regions: proximity between regions, distance to the beach, presence of a central square, surrounding density and compactness region.

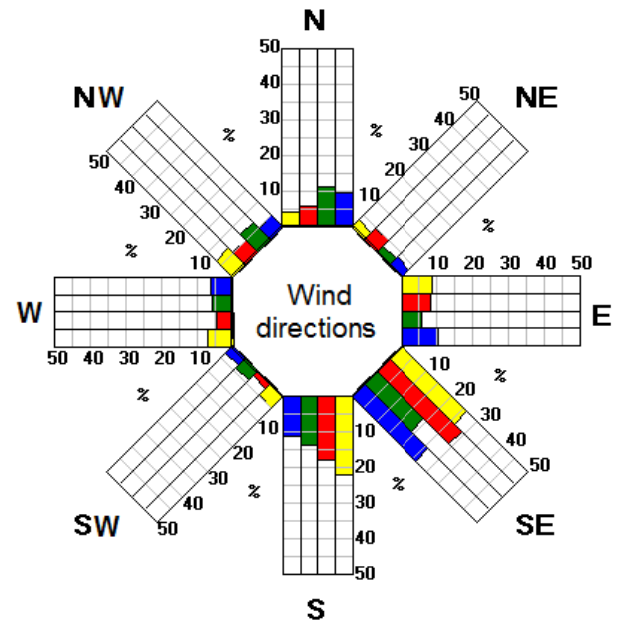

(a)

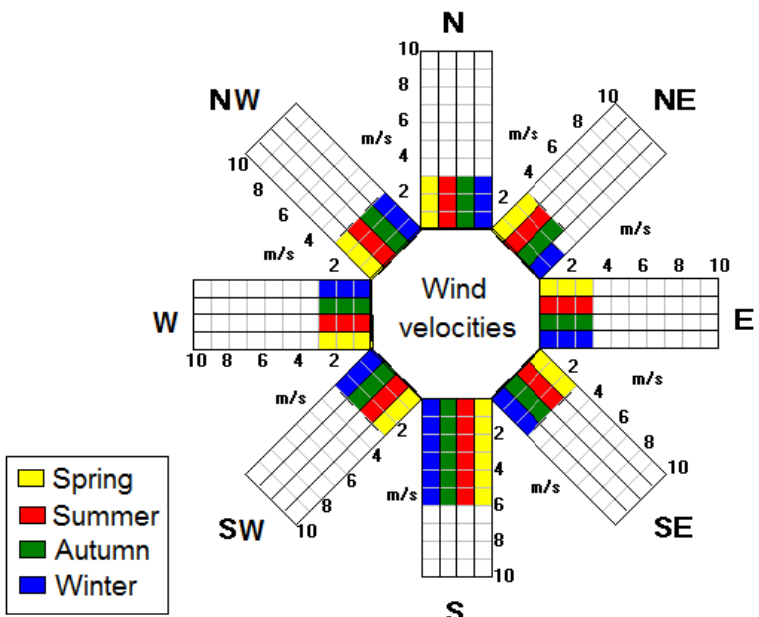

(b)

Fig. 14 Wind data obtained using the software Solar in the city of Rio de Janeiro: (a) wind velocities; (b) directions (LabEEE UFSC (Laboratory for Energy Efficiency in Buildings_-Federal University of Santa Catarina)).

most of the neighborhood, led to the emergence of the great towers of the waterfront hotels. In Fig. 10, the evolution of the heights of the buildings can be seen from Copacabana.

The evolutionary line related to the heights of the buildings of the two neighborhoods, shown in Fig. 11, allows us to observe the differences from the established dynamics of occupation of Copacabana and Ipanema. Both districts, side by side, can be seen in Fig.12, in the 1950s and today.

\section{Methodological Procedures}

The studied blocks, one of each of the neighborhoods, were selected according to the factors that allowed establishing a relation between the two regions: proximity between regions, distance to the 
beach, presence of a central square and surrounding density and compactness of the region (Fig. 13).

For the 2D (two-dimensional) data, the cartography of the Rio de Janeiro City were used ${ }^{3}$ and then an on-site survey of the region was conducted: urban morphology, pedestrian and vehicles routes, lining of the natural and artificial urban, presence of water mirrors and so on.

For the next stage of the survey, it was necessary to obtain the climate data for the experimental simulations. The wind velocities and directions for the city of Rio de Janeiro were obtained using the software Solar [17] and are shown in Fig. 14. For the experiments, the highest frequency of winds from the south-east in summer and the maximum speed of $3 \mathrm{~m} / \mathrm{s}$ were adopted. Indeed, the predominance of south-east winds occurs in all seasons.

From these data, the models were generated (Fig. 15) for the experiments with the proper dimensions to the test table and the proper materials. The materials should be sturdy enough for the experiments and the colors should be selected to allow better visualization.

The models were built in paper "Paraná" (strong paper) and the black background is the plan reversed, that is, the lines of demarcation of land and streets are white. Thus, the visualization of the white sand is more immediate.

Once the experiments were performed, image files were generated with the simulation results for analysis and presentation.

\section{Results and Discussions}

In Figs. 16-20, the results for the experimental simulations can be seen by adopting these wind directions: southeast, south, east, west and southwest, respectively. The arrow inside the figures indicates the wind direction for each case.

\footnotetext{
${ }^{3}$ Armazém de Dados, Instituto Municipal de Urbanismo Pereira Passos-IPP, Prefeitura da Cidade do Rio de Janeiro (Data Warehouse, Municipal Institute of Urbanism Pereira Passos-IPP, City Hall of Rio de Janeiro), Brazil, 2011. Available: www.rio.rj.gov.br/web/ipp.
}

The southeast wind direction is the most common in Rio de Janeiro City in all seasons of the year.

The results obtained for this wind direction (Fig. 16) show that the ventilation in the Ipanema area (Fig. 16b) is able to reach even though the internal streets are farther from the sea. The fact that one of the ways of Ipanema is southeastward facilitated the penetration of ventilation. Also, the width of the streets is broader, especially this street which arrives at the square coming from the southeast direction. In the case of Copacabana, although some streets are direct to face southeast, they are narrow streets (ratio $W / H$ is below 1), and the ventilation is obstructed by dense blocks of buildings.

The south wind direction presents an important incidence in this region and is the direction where the highest wind velocities were found.

Because of bigger velocity of south winds, this is perhaps the most able direction that penetrates the internal roads of the neighborhoods and obtains access of even more internal areas of the blocks and the very square.

The southwest wind direction presents the worst results for Copacabana district. In many streets, there was an accumulation of white sand, which records that these sites may have higher temperatures. However, the southwest wind shows the best occurrence when evaluating the Ipanema district.

For all wind incidences, that is, southeast, south, east, west and southwest, the results of experimental simulations indicated the best distribution of ventilation in blocks from Ipanema neighborhood. The wind was able to penetrate the streets that make up the study area. A lower incidence of stagnant areas resulting in reduced possibility of forming heat islands was observed.

In Fig. 21, the results for all wind directions are shown and can be observed side by side with the ventilated areas marked (orange color) for better viewing.

From the results of the experiments, it is apparent that the blocks from Ipanema are more permeable and 


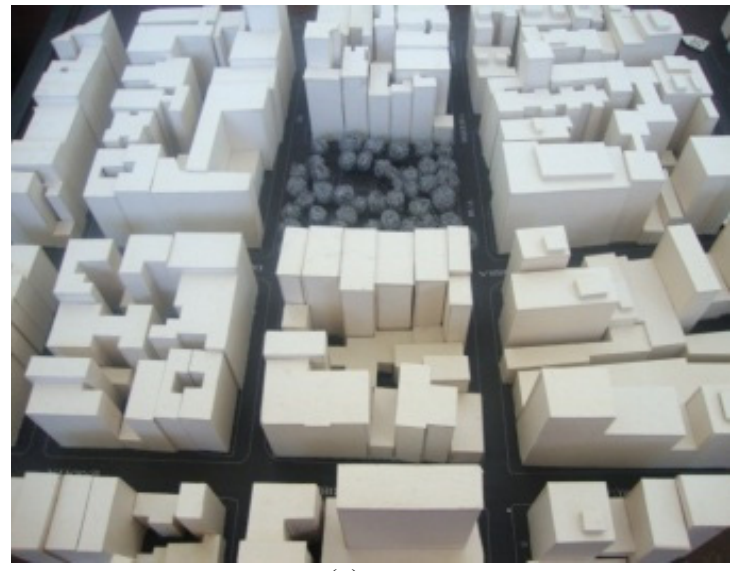

(a)

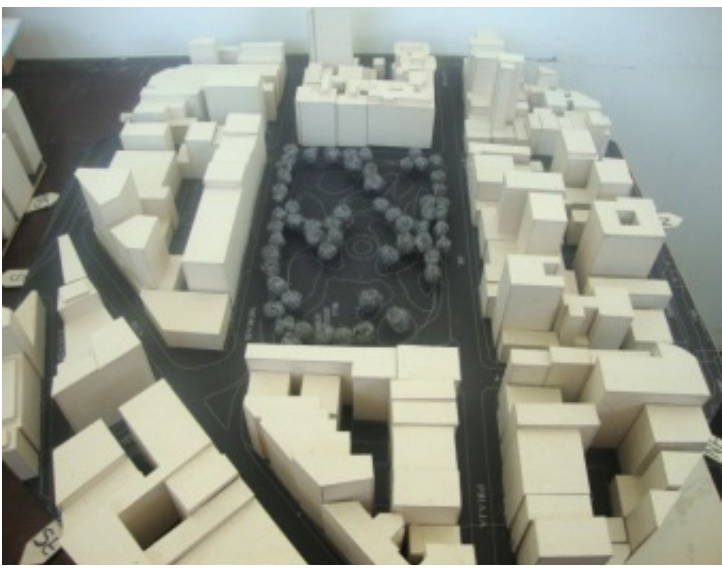

(b)

Fig. 15 Models: (a) Copacabana; (b) Ipanema.

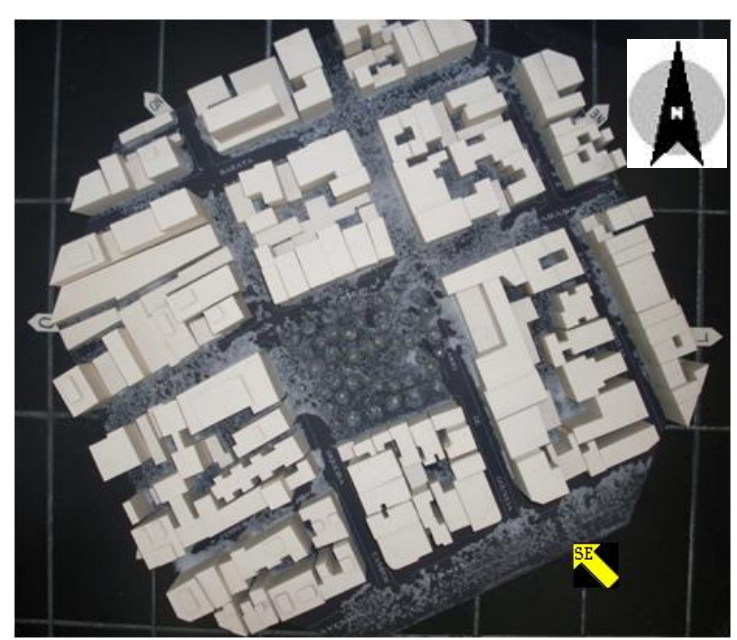

(a)

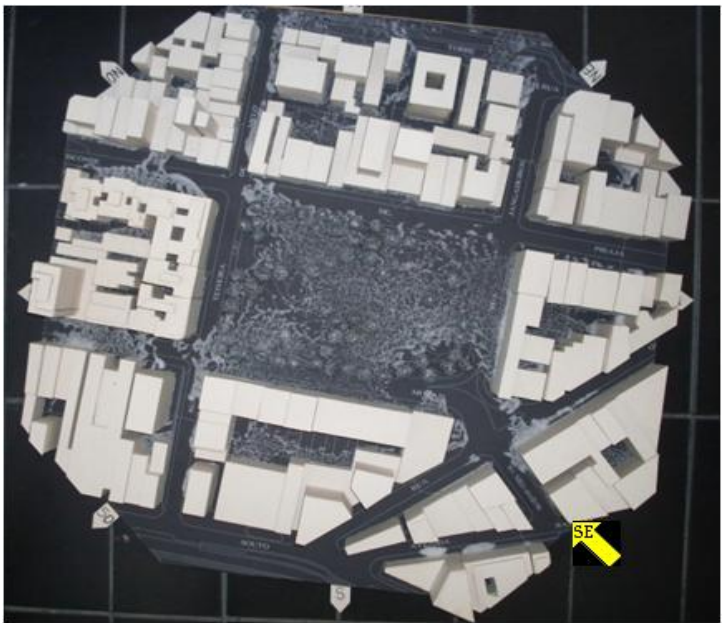

(b)

Fig. 16 Southeast: (a) Copacabana; (b) Ipanema.

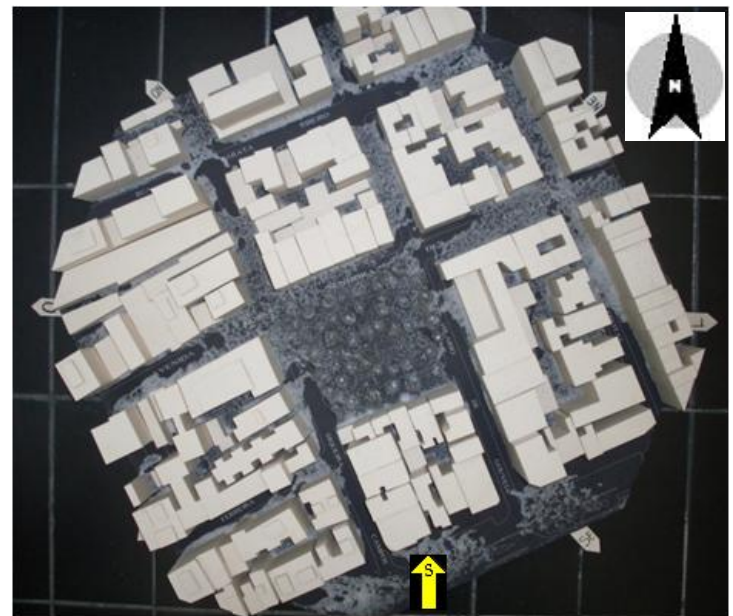

(a)

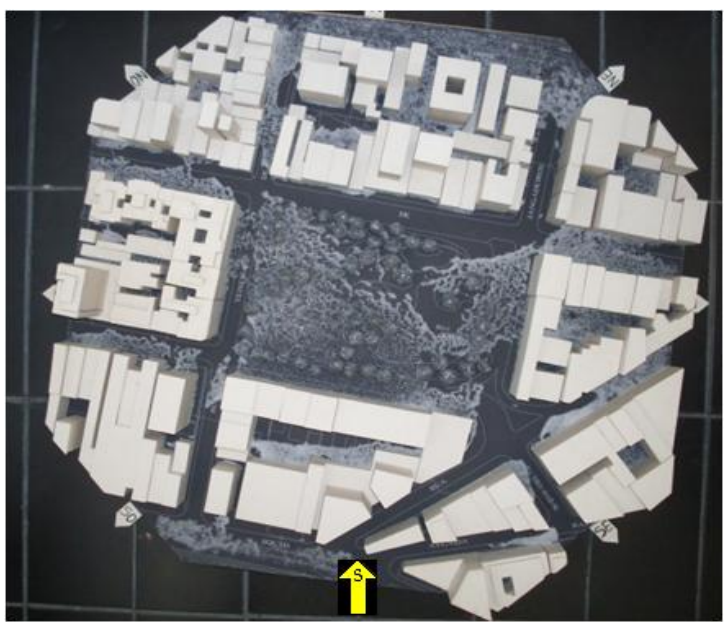

(b)

Fig. 17 South: (a) Copacabana; (b) Ipanema. 


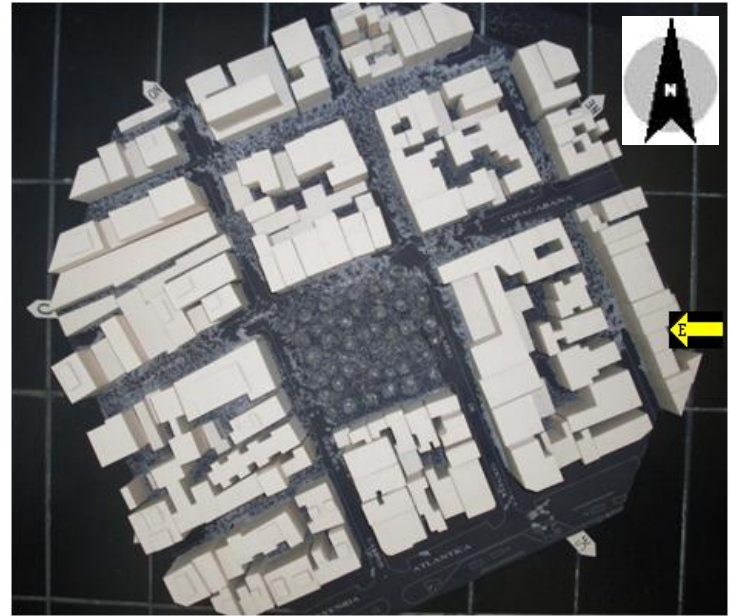

(a)

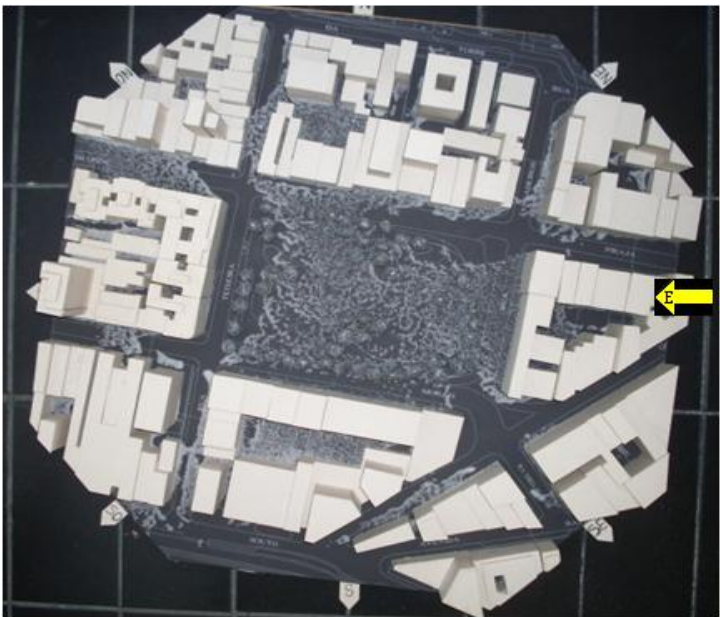

(b)

Fig. 18 East: (a) Copacabana; (b) Ipanema.

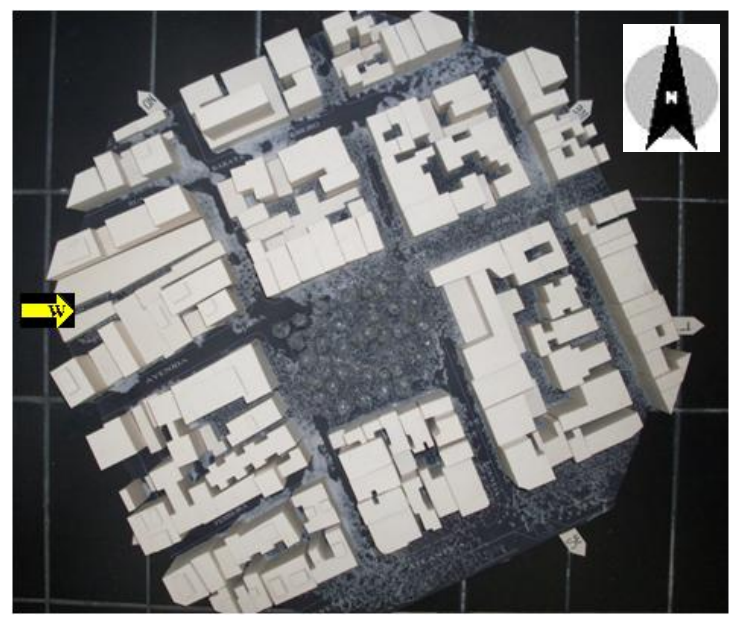

(a)

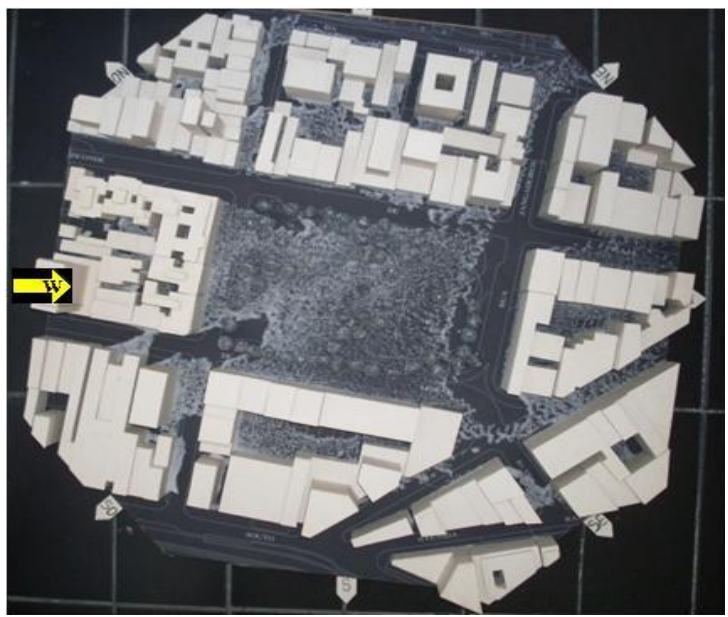

(b)

Fig. 19 West: (a) Copacabana; (b) Ipanema.

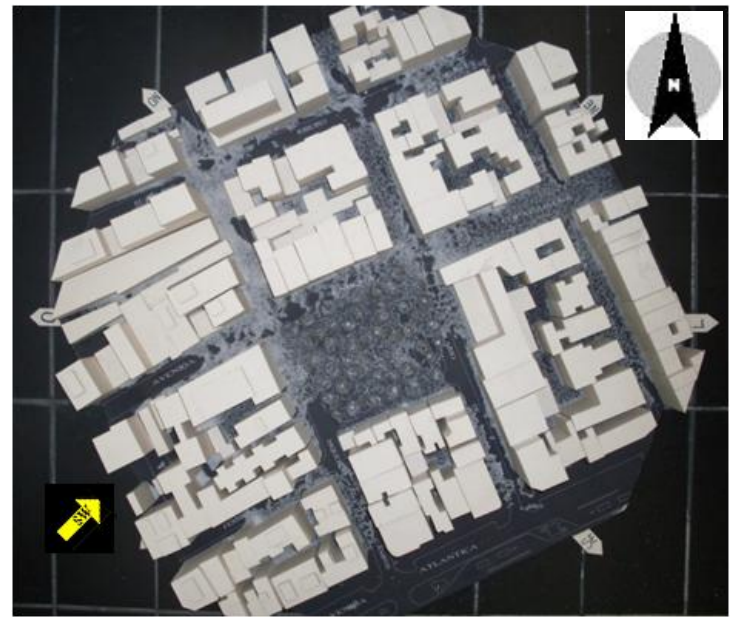

(a)

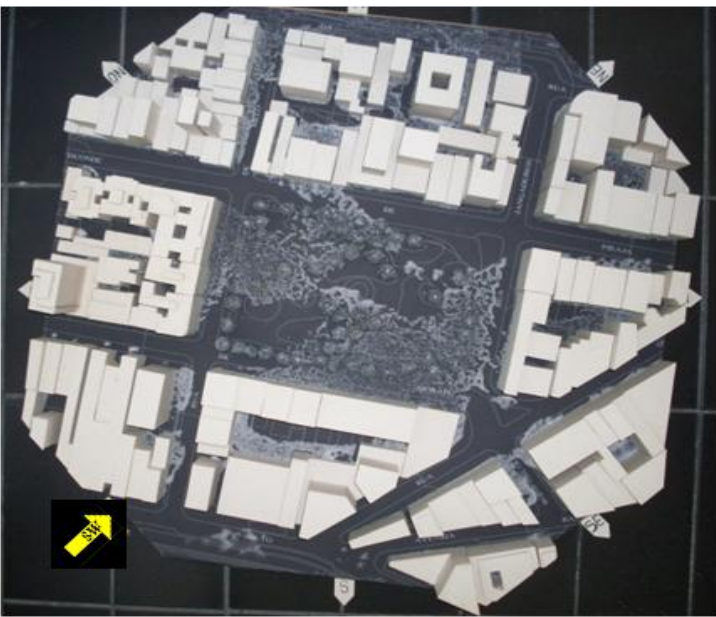

(b)

Fig. 20 Southwest: (a) Copacabana; (b) Ipanema. 


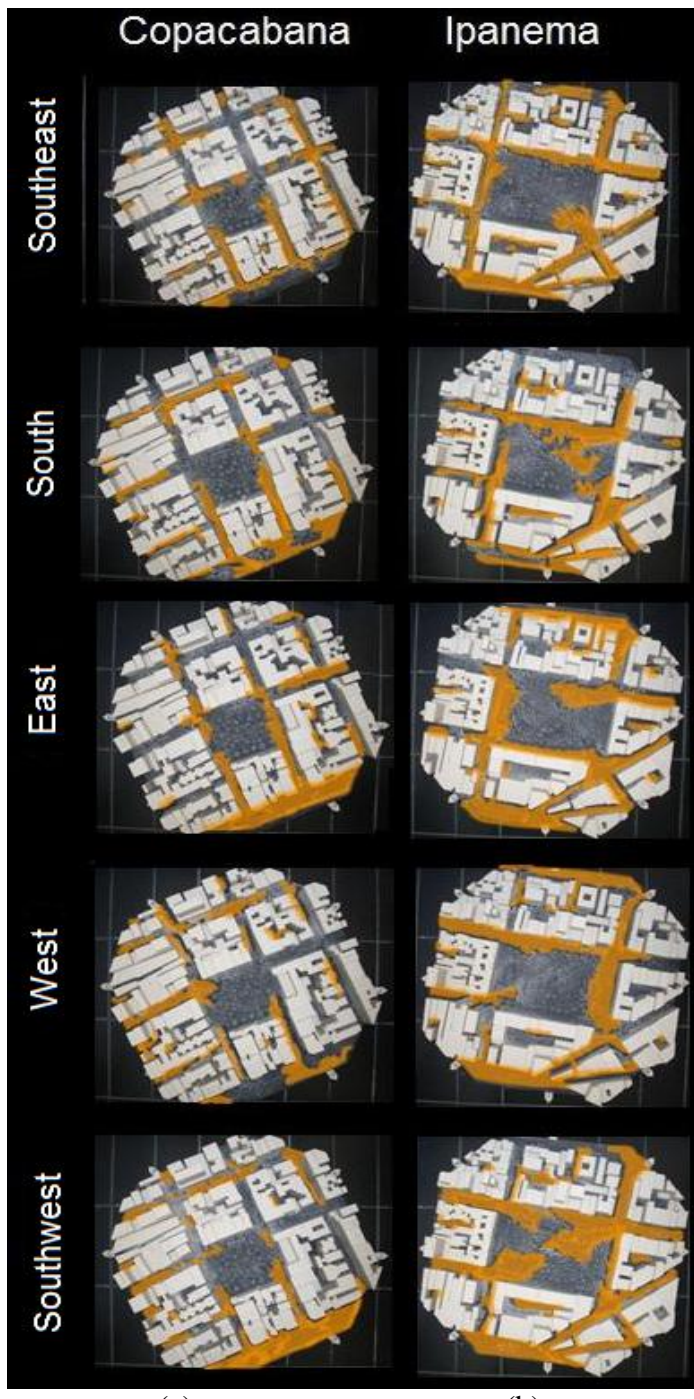

(a)

(b)

Fig. 21 Comparative wind directions: (a) Ipanema; (b) Copacabana.

therefore presented better ventilation. The highest incidence of ventilation is due to the fact that the neighborhood of Ipanema has buildings with fixtures that are less homogeneous and larger open areas within the blocks. Moreover, their paths are wider, with higher values for the $W / H$ ratio if compared with Copacabana. The blocks are bigger and include a variety of forms, exhibiting a discontinuity mass. The Ipanema blocks have triangular, trapezoidal and rectangular shapes. In Copacabana, the blocks are mostly similar and have rectangular shape.

The results allow a direct assessment of urban morphology with ventilation and expose the

importance of similar studies for the evaluation of urban projects and interference in areas already built.

\section{Conclusions}

From the results, it is possible to observe that the urban morphology is able to represent a strong influence on the direction and strength of winds. The permeability of the wind across the urban mesh is essential to improve ventilation on the internal areas of the neighborhood.

In this paper, two strategies for decision support design were used to establish the quality of the distance between the buildings in the region: the wind tunnel for experimental simulations and the $W / H$ ratio. Both were able to indicate that the neighborhood of Copacabana has a poorer ventilation as a result of the inadequacy (or lack) of interventions in the urban fabric.

In the case of Copacabana, where a barrier of buildings with the virtually same height blocked the entrance of the wind, there is a depletion of ventilation in the innermost areas of the district. Even in the region of Serzedelo Correa's Square and its surroundings, the occurrence of areas of stagnation can be observed.

If these areas are associated with heatstroke, it may result in higher heating, which does not contribute to the dispersion of gas emissions from buses and cars.

In Ipanema, ventilation has a broader scale and allows the ventilation to penetrate the innermost part of the neighborhood. For all wind directions tested, the results allowed the observation of the penetration of wind in the uttermost parts of the neighborhood.

Thus, it is important to perform studies related to the height of buildings, urban occupation and ventilation for both deployment of new cities or even for intervention in existent neighborhoods. Urban morphologies that allow barriers may impair the passage of winds, but design strategies can redirect winds contributing to the environmental comfort of the users of urban spaces. The vegetation is a great ally because it functions as an area of shading and contributes to lowering the temperature. 
The wind tunnel is an important tool to aid design decisions. It still allows the evaluation of different configurations in the design phase, both in urban and architectural models. This is an important factor in reducing design flaws, resulting in reduced financial and environmental costs.

\section{Acknowledgments}

The financial help is provided by the Brazilian funding agencies: $\mathrm{CNPq}$ (National Council for Scientific and Technological Development), CAPES (Coordination for the Improvement of Higher Education Personnel) and FAPERJ (Foundation for Support of Research in the State of Rio de Janeiro).

\section{References}

[1] Carneiro, M. S. C., Bastos, L. D., Castro, M. S., Drach, P. R. C., and Corbella, O. D. 2012. Estudo Experimental Comparativo da Ventilação na Região portuáRia do Rio de Janeiro (Comparative Experimental Study of Ventilation in the Port Area of Rio de Janeiro). In Proceedings of Congresso Luso Brasileiro Para o Planejamento Urbano, Regional, Integrado e Sustentável-PLURIS (Luso Brasileiro for Urban Planning, Regional, Integrated and Sustainable), 1-12. (in Portugal)

[2] Abreu, M. A. 1987. Evolução Urbana do Rio de Janeiro (Uraban Development in Rio de Janeiro). Rio de Janeiro: Iplanrio/Zahar Editor. (in Portugal)

[3] Berger, E., and Berger, P. 1959. História dos Subúrbios: Copacabana (History of the Suburbs: Copacabana). Departamento de História e Documentação da Prefeitura do Distrito Federal-Rio de Janeiro (Department of History and Documentation of the Municipality of Rio de Janeiro Federal). (in Portugal)

[4] Cardoso, E. D., Vaz, L. F., Albernaz, M. P., Aizen, M., and Pechman, R. M. 1986. História dos Bairros do Rio de Janeiro-Copacabana (History of Neighborhood of Rio de Janeiro-Copacabana). Rio de Janeiro: Editora Index. (in Portugal)

[5] Drach, P. R. C., and Corbella, O. D. 2010. "Estudo das Alterações na Dinâmica da Ventilação e da Temperatura na Região Central do Rio de Janeiro: Mudanças na Ocupação do Solo Urbano (Study of Changes in Dynamic of Ventilation and Temperature in the Central Region of Rio de Janeiro: Changes in Land Use In Urban).” In Proceedings of the 4th Luso-Brazilian Congress for
Urban Planning, Regional, Integrated and Sustainable, 1-12. (in Portugal)

[6] Barbosa, G. S., Drach, P. R. C., and Corbella, O. D. 2010. “A Comparative Study of Sprawling and Compact Areas in Hot and Cold Regions: Way to Sustainable Development of Cities.” In Proceedings of World Renewable Energy Congress 2010, 1-6.

[7] Barbosa, G. S., Drach, P. R. C., and Corbella, O. D. 2010. "Um Estudo Comparativo de Regiões Espraiadas e Compactas: Caminho para o Desenvolvimento de Cidades Sustentáveis (A Comparative Study of Regions Espraiadas and Compact: Path to Development of Sustainable Cities).” In Proceedings of Congresso Internacional Sustentabilidade e Habitação de Interesse Social-CHIS (International Congress Sustainability and Social Housing), 1-10. (in Portugal)

[8] Alva, E. N. 1997. Metrópolis (in) Sustentáveis (Metropolis (un) Sustainable). Rio de Janeiro: Editora Relume Dumarã. (inPortugal)

[9] Romero, M. A. B. 2001. Arquitetura Bioclimática do Espaço Público (Bioclimatic Architecture of Open Spaces). Brazillia: Editora Universidade de Brasília.

[10] Romero, M. A. B. 2009. Correlação entre o Microclima Urbano e a Configuração do Espaço Residencial de Brasília (Correlation between the Microclimate and the Urban Residential Space Configuration in Brasilia). Presented at ENCAC_-Encontro Nacional de Conforto no Ambiente Construído (Comfort National Meeting in the Built Environment), Brazil.

[11] Loredo-Souza, A. M., and Paluch, M. J. 2005. Projeto do Túnel de Vento FAU-UFRJ. Laboratório de Aerodinâmica das Construções, LAC-DECIV/PPGEC-UFRGS (Wind Tunnel Project FAU/UFRJ-The Building Aerodynamics Laboratory-LAC/DECIV/PPGEC-from Federal Universityof Rio Grande do Sul). Brazil: UFRGS. (in Portugal)

[12] Corbella, O. D., Loredo-Souza, A. M., and Paluch, M. J. 2007. “Apresentação do Túnel de Vento da FAU/UFRJ." Presented at IX Encontro Nacional de Conforto no Ambiente Construído e V Encontro Latino-Americano de Conforto no Ambiente Construído, Brazil.

[13] Drach, P. R. C., Vasconcellos, V. M. N., and Corbella, O. D. 2009. "A Study of Ventilation in the Urban Space around Largo do Machado: A Square in Rio de Janeiro City-Brazil.” Presented at the 1st International Conference on Sustainable Cities, Morelia, Michoacán, México.

[14] ECV (LabEEE, Departamento de Engenharia Civil). 2012. Solar Software. ECV-UFSC. (in Portugal) 